\title{
A benzilamino-oxidase (BzAO) em portadores de adenocarcinoma gástrico avançado ${ }^{1}$
}

\author{
Nelson Adami Andreollo ${ }^{2}$ \\ Luiz Baldini Neto ${ }^{3}$ \\ João Paulo Toledo ${ }^{4}$ \\ Marina Raquel Araújo ${ }^{5}$ \\ Luiz Roberto Lopes ${ }^{6}$ \\ Rachel Lewinsohn ${ }^{7}$
}

\begin{abstract}
Andreollo NA, Baldini Neto L, Toledo JP, Araújo MR, Lopes LR, Lewinsohn R. A benzilaminooxidase (BzAO) em portadores de adenocarcinoma gástrico avançado. Acta Cir Bras [serial online] 2003 Mar-Abr;18(2). Disponível em URL: http://www.scielo.br/acb.

RESUMO - Objetivo: Realizar dosagens da benzilamino-oxidase (BzAO), uma enzima tissular localizada na túnica média dos vasos sanguíneos, mais precisamente no músculo liso, em fragmentos tumorais e não tumorais de peças cirúrgicas ressecadas de portadores de adenocarcinoma gástrico avançado. Métodos: Foram incluídos no estudo 24 doentes (18 masculinos e seis femininos com média de idade de 55,4 anos). Quanto à localização do tumor, eram 11 do antro gástrico, nove do corpo, dois da cárdia, um do corpo e antro e um do fundo, sendo que 12 doentes foram submetidos a gastrectomia subtotal e os demais a gastrectomia total com esplenectomia, todos com linfadenectomia a D2. As dosagens de BzAO foram correlacionadas com idade, sexo, tempo de história da doença, local do tumor no estômago, tipo histopatólogico e cirurgia realizada. Resultados: A atividade enzimática da BzAO nos tecidos gástricos normais variou de $22,9 \mathrm{mM}$ a $111 \mathrm{mM}$ (média de 57,1), sendo superior nos tecidos tumorais em todos os casos, variando de $35,5 \mathrm{mM}$ a $148 \mathrm{mM}$ (média de 70,7). A análise estatística pelo teste $t$ de student mostrou diferença significativa entre as duas dosagens (desvio padrão de 2,373 e $p=0,0263$, portanto $p<0,05$ ). Conclusão: As dosagens de BzAO foram mais elevadas nos fragmentos tumorais gástricos, sugerindo existir correlação entre a BzAO e a angiogênese, e, portanto, a possibilidade de utilização de terapias antiangiogênicas que atuem inibindo o crescimento tumoral e metastático.
\end{abstract}

DESCRITORES - Benzilamino-oxidase. Estômago. Adenocarcinoma gástrico. Angiogênese.

\section{Introdução}

A BzAO foi descoberta acidentalmente quando Bergeret e col. ${ }^{1}$ estudaram o efeito do antimalárico Primaquin no sangue de mamíferos e descobriram no soro equino uma enzima com propriedades reminescentes da espermina-oxidase plasmática, porém sem a ação rápida desta contra espermina e a esperimidina. Provisoriamente foi denominada "benzilamino-oxidase"

1. Trabalho realizado no Laboratório de Enzimologia e Carcinogênese Experimental do Núcleo de Medicina e Cirurgia Experimental do Departamento de Cirurgia, Faculdade de Ciências Médicas da Universidade Estadual de Campinas (UNICAMP), São Paulo.

2. Professor Associado do Departamento de Cirurgia.

3. Aluno de Graduação, Bolsista de Iniciação Científica do CNPq.

4. Aluno de Graduação, Bolsista de Iniciação Científica da FAPESP.

5. Bióloga do Laboratório.

6. Professor Assistente, Doutor do Departamento de Cirurgia.

7. Professor Assistente, Doutora Convidada do Departamento de Cirurgia. 
por possuir forte atividade contra a benzilamina $(\mathrm{Bz}) \mathrm{e}$ porque se tornou imediatamente evidente que as propriedades da enzima plasmática equina diferiam fundamentalmente das pertencentes à amino-oxidase intracelular ${ }^{2}$.

Alguns anos depois foi demostrado por Blaschko que a amino oxidase plasmática (AO) tem distribuição muito mais ampla em mamíferos do que se sabia, embora já se verificasse atividade sérica da $\mathrm{BzAO} \mathrm{em}$ três espécies de primatas. No ano seguinte, McEwen e Cohen ${ }^{3}$ descobriram que o plasma ou soro humano contém uma $\mathrm{AO}$ solúvel capaz de catalizar a conversão de Bz para benzadeído, $\mathrm{AO}$ essa que se distingue tanto da ceruslosplamina quanto da diamino-oxidase. Foi ainda $\mathrm{McEwen}^{4,5}$ que purificou e identificou a enzima do plasma humano e estudou sua cinética, utilizando uma técnica espectofotométrica baseado nos métodos descritos por Tabor e col. ${ }^{6}$. Os estudos que se seguiram tratam da $\mathrm{AO}$ circulante em várias espécies de mamíferos, além da descrição de anomalias da atividade enzimática no plasma ou soro de pacientes com insuficiência cardíaca congestiva e cirrose hepática, seguiram-se estudos da atividade da BzAO em populações normais e algumas doenças humanas?

Estudos recentes de Lewinsohn e Araújo ${ }^{8} \mathrm{em}$ pacientes portadores de câncer de esôfago e colo de útero demonstraram variações significativas em relação aos tecidos normais e, concluem que a BzAO pode ser útil no diagnóstico diferencial de câncer e na monitorização de pacientes em tratamento para diversas doenças neoplásicas.

Não encontramos na literatura consultada nenhuma pesquisa realizada especificamente para estudo de BzAO em portadores de câncer gástrico.

$\mathrm{O}$ carcinoma gástrico é a neoplasia maligna mais comum do trato gastrointestinal. A sua ocorrência em nosso meio é bem elevada comprometendo, principalmente, pacientes na faixa etária dos 50 aos 70 anos. Estima-se atualmente que o Brasil tenha uma das maiores taxas desta neoplasia maligna no mundo, atingindo 30 (trinta) casos /100.000 habitantes / ano, em algumas regiões. Enquanto no Japão o diagnóstico desta neoplasia é feito em cerca de $50 \%$ dos casos no estadio precoce, na maioria dos países ocidentais, o diagnóstico precoce ocorre apenas em 10\% dos doentes. Assim, a grande maioria dos doentes chega aos médicos com doença localmente avançada ${ }^{9}$.

Assim considerando, esta pesquisa tem por objetivos a dosagem da atividade da $\mathrm{BzAO}$ em fragmentos de área tumoral obtidos de peças cirúrgicas de doentes portadores de adenocarcinoma gástrico avançado submetidos a gastrectomia total ou subtotal, comparada com a dosagem em fragmentos de área não tumoral.

\section{Métodos}

Após a aprovação pelo Comitê de Ética em Pesquisa, e mediante consentimento informado foram obtidos fragmentos de estômagos de 24 doentes portadores de adenocarcinoma gástrico avançado, tratados cirurgicamente na Disciplina de Moléstias do Aparelho Digestivo, Departamento de Cirurgia do Hospital de Clínicas da Faculdade de Ciências Médicas - Universidade Estadual de Campinas, de várias faixas etárias e ambos os sexos. O diagnóstico foi realizado pelo estudo anatomopatológico de fragmentos obtidos de endoscopia digestiva e biópsias no pré-operatório. Foram 18 masculinos e seis femininos, com faixa etária variando de 32 a 75 anos (média de 55,4 anos).

Quanto à localização do tumor, foram 11 do antro gástrico, nove do corpo, dois da cárdia, um do corpo e antro e um do fundo. Portanto, 12 doentes foram submetidos a gastrectomia subtotal e os demais a gastrectomia total com esplenectomia, todos com linfadenectomia a D2 e ressecção do omento.

A metodização utilizada nesta pesquisa consistiu em:

\section{a) Informações clínicas do doente:}

Foram obtidas do seu prontuário médico, relacionando: idade, sexo, tempo de história da doença, local do tumor no estômago, tipo histopatólogico e procedimento cirúrgico realizado.

b) Coleta dos fragmentos das peças:

Imediatamente após ressecadas as peças cirúrgicas, procedeu-se a abertura do estômago e individualização da área tumoral. Em seguida, foram obtidos dois fragmentos para estudo:

b1) Fragmento do tumor, envolvendo toda a parede gástrica de cerca de $1 \mathrm{~cm}$ por $1 \mathrm{~cm}$, colocado em frasco estéril contendo soro fisiológico $0,9 \%$ e imediatamente levado ao congelador $\left(0^{\circ} \mathrm{C}\right)$. Toda a peça ressecada foi enviada para estudo histopatológico e confirmação de neoplasia maligna.

b2) Fragmento do estômago envolvendo toda a parede gástrica, em local distante da área tumoral, considerado livre de tumor, de $1 \mathrm{~cm}$ por $1 \mathrm{~cm}$, colocado em frasco estéril contendo soro fisiológico $0,9 \%$ e imediatamente levado ao congelador $\left(0^{\circ} \mathrm{C}\right)$. Este fragmento serviu como grupo controle para efeito de comparação com o da área tumoral. Também foi enviada para estudo histopatológico excluindo-se, assim, a presença de adenocarcinoma gástrico. 


\section{c) Dosagens da atividade da BzAO:}

As dosagens foram realizadas no Laboratório de Enzimologia e Carcinogênese Experimental do Núcleo de Medicina e Cirurgia Experimental da Universidade de Campinas, conforme técnica descrita a seguir:

\section{c1 ) Preparação de homogenatos:}

Os fragmentos de tecido foram seccionados em fragmentos menores com o auxílio de uma tesoura e em seguida macerados em homogeneizador de vidro ou em triturador elétrico. O tampão de fosfato de potássio $1 \mathrm{mM} \mathrm{em} \mathrm{pH}=7,2$ foi adicionado ao material homogeneizado.

d) Dosagem espectrofotométrica da desaminação da Benzilamina:

Foi realizada a partir de seis concentrações de benzilamina, para maior segurança, quais sejam: 800 $\mathrm{mM}$ (400 mM final); $400 \mathrm{mM}$ (200 mM final); 100 $\mathrm{mM}$ (50 mM final); $200 \mathrm{mM}$ (100 mM final) e $50 \mathrm{mM}$ (25 mM final).

e) Curva de linearidade de tempo e curva de linearidade de concentração de enzimas:

As dosagens enzimáticas foram cuidadosamente controladas quanto ao tempo de incubação, temperatura e concentração da enzima, sendo que os valores ótimos para cada um desses fatores foram estabelecidos da seguinte forma:

e.1) Curva de linearidade de tempo de incubação:

Estabelecida em relação aos homogeneizados de tecidos, no tempo de 30 minutos a partir de uma curva onde se usam 10, 20, 30 e 45 minutos de incubação, na temperatura de $37^{\circ} \mathrm{C}$. enzima:

e.2) Curva de linearidade de concentração de

Foi estabelecida uma curva de concentração da enzima onde se utiliza o homogeneizado total (HT), sendo o HT, com proteína em torno de 9.0 ou $10.0 \mathrm{mg} /$ $\mathrm{ml}, 1 / 2$ do HT e $1 / 8$ do HT, incubando-se o material por 30 minutos, uma vez que os tecidos apresentam leitura altas, sendo necessário diluições posteriores à homogeneização ${ }^{4,5,6}$.

\section{Resultados}

Os diâmetros dos tumores variaram de 25 a 135 $\mathrm{mm}$ (média de 62,9 $\mathrm{mm}$ ). Todos invadiam a serosa gástrica, sendo que oito apresentavam metástases para as cadeias linfonodais do nível 1 e 15 do nível 2 e somente um caso não apresentava acometimento linfonodal. O número de linfonodos acometidos variou de 1 a
36 (média de 7 linfonodos), sendo que o número total de linfonodos dissecados variou de 4 a 40 (média de 17 linfonodos).

A atividade enzimática da BzAO nos tecidos gástricos normais variou de $22,9 \mathrm{mM}$ a $111 \mathrm{mM}$ (média de 57,1). A atividade foi superior nos tecidos tumorais em todos os casos, variando de $35,5 \mathrm{mM}$ a $148 \mathrm{mM}$ (média de 70,7).

O Gráfico 1 mostra as dosagens de BzAO nos tecidos normais e tumorais dos doentes. Notar que a curva das dosagens de BzAO nos tecidos tumorais foi superior na maioria dos doentes. A análise estatística pelo teste $t$ de student mostrou diferença significativa entre as duas dosagens (desvio padrão de 2,373 e p = $0,0263$, portanto $\mathrm{p}<0,05)$.

Quando foram analisadas outras variáveis, não foi encontrada diferença significativa em relação à idade, sexo, local do tumor, tipo histopatológico, acometimento linfonodal e a invasão tumoral vascular e perineural e cirurgia realizada.

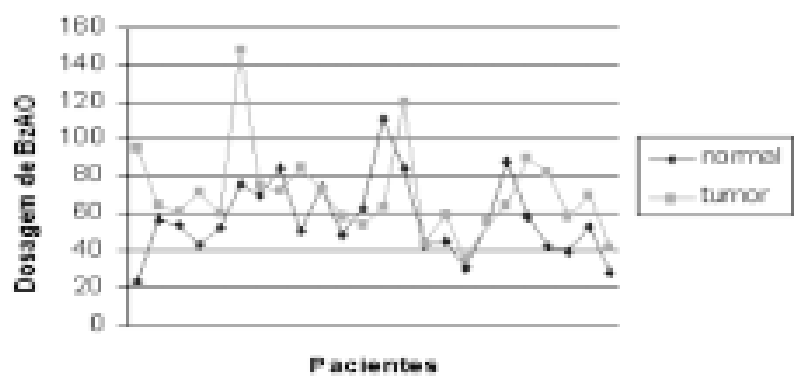

Gráfico 1: Atividade enzimática específica da BzAO de 24 pacientes estudados.

\section{Discussão}

Em 1977, Lewinsohn descreveu variações da atividade sérica da $\mathrm{BzAO}$ em grandes queimados e em pacientes com câncer ${ }^{10}$. Notando o virtual desaparecimento da atividade circulante, após queimaduras de $18 \%$ a $20 \%$ ou mais da superfície corpórea, verificou que a velocidade de queda inicial dessa atividade mantinha relação com a evolução do caso nas primeiras 72 horas após o acidente. Todos os grandes queimados apresentavam queda drástica da atividade da BzAO sérica: quanto mais rápida esta queda, pior o prognóstico. Por outro lado, observou que o retorno a níveis normais de atividade é invariavelmente lento (seis meses no mínimo), sem correlação com estado do paciente. Estudos subseqüentes em pacientes com câncer revelaram atividade baixissíma da BzAO sérica em portadores de tumores sólidos, com concentração sérica dentro de 
limites normais. Em todos os casos estudados, houve estreita relação entre o estado clínico dos pacientes com tumores sólidos e a dosagem da BzAO, principalmente após cirurgia e/ou o início da quimioterapia ${ }^{10}$.

Não obstante seu caráter preliminar, estas observações assinalavam a possibilidade de dosagem da BzAO tornar-se um valioso adjunto diagnóstico, prognóstico e eventualmente terapêutico em grandes queimaduras e em certos tipos de neoplasias, particularmente em tumores sólidos. Um editorial do Lancet ${ }^{11}$ chamou atenção para esses aspectos das investigações da autora, isto é, a possível utilidade da dosagem de BzAO para a conduta médica frente a pacientes com doenças neoplásicas.

Entretanto, na dependência de informações básicas sobre a localização da BzAO, totalmente desconhecida até então, e de maiores dados sobre suas propriedades físico-químicas, a sua eventual aplicação clínica nos termos acima citados, teria valor estritamente limitado. Consequentemente, as pesquisas e os estudos seguintes foram sobre a atividade da BzAO e das MAOs em tecidos humanos e de ratos $^{12}$.

Tanto a BzAO quanto o monoamio-oxidase (MAO) A e B foram encontrados em quase todos os tecidos investigados, verificando-se, porém, que embora as três enzimas tenham distribuição e atividades semelhantes nos tecidos de ratos e do homem, seu comportamento frente a substratos e inibidores apresenta diferenças que excluem a extrapolação de resultados entre espécies e mesmo entre tecidos da mesma espécie. Evidenciouse, ao contrário das hipóteses em pauta até então, que a BzAO é uma enzima tissular, cuja presença na circulação sanguínea pode ser interpretada como fenômeno de escape dos tecidos ${ }^{12}$.

Assim, mediante rádio-microensaio de procedimentos histoquímicos e de espectofotometria foi mostrada a localização da BzAO na túnica média do vaso sangüíneo e não do endotélio, conforme afirmavam vários autores ${ }^{13}$. Os estudos subsequentes de Lewinsohn ${ }^{14}$ indicam sua localização mais precisa no músculo liso.

Embora qualquer hipótese a respeito da função BzAO no músculo liso permaneça especulativa até o presente momento, a evidência das observações clínicas sugere que tal função se relaciona com a atividade secretora da célula, e não a vasomotora. Levando em conta os níveis ínfimos no plasma ou soro, comparados com atividade encontrada na parede vascular, é provável que a degradação do substrato fisiológico da BzAO não ocorra na circulação sangüínea, mas em nível intracelular na intimidade dos tecidos.
A origem desses valores alterados e, o que é mais importante, as funções da enzima devem ser procuradas, sem dúvida, no músculo liso; possivelmente, na atividade secretora da célula. As observações clínicolaboratoriais de Lewinsohn ${ }^{14}$ sugerem que a enzima intervém em algum ponto da angiogênese, especificamente tanto na produção como na reabsorção de elementos (colágeno, elastina, e outros) que integram os tecidos em que predomina o músculo liso, principalmente na parede vascular.

A angiogênese é o processo pelo qual uma estrutura ou tecido estimula a formação de novos vasos sangüíneos. É um processo muito controlado e dependente de inúmeros fatores estimuladores e inibidores. Os recentes avanços na terapia do câncer em geral foram justamente relacionados ao desenvolvimento de agentes antiangiogênicos. E o conceito antiangiogênico parece unificar atualmente as futuras pespectivas na luta contra o câncer e suas metástases. Várias são as terapias antiangiogênicas em estudo atualmente, como o trombospondin, o interferon, os inibidores das metaloproteinases, a angiostatina, a endostatina e alguns agentes farmacológicos como a talidomida e o carboxiamidotriazol ${ }^{15}$.

$\mathrm{Na}$ literatura consultada não foi encontrada nenhuma pesquisa referente à dosagem tissular da $\mathrm{BzAO} \mathrm{em}$ portadores de adenocarcinoma gástrico. Desse modo, na presente pesquisa foi estudado a atividade enzimática da BzAO em fragmentos de peças cirúrgicas ressecadas, tanto da área tumoral, como da área gástrica normal sem presença de neoplasia, de portadores de adenocarcinoma gástrico avançado.

Nesta pesquisa cada um dos doentes estudados foi controle dele próprio. E, coincidentemente, a maioria era do sexo masculino. A interpretação e o real significado da BzAO ser mais elevada nos fragmentos tumorais não é conhecido, porém nossa suposição é pelo fato do tecido tumoral ser habitualmente mais vascularizado que o tecido normal. No Gráfico 1 podese observar que os resultados são bem homogêneos em todos os doentes, com diferença estatisticamente significativa entre as dosagens da enzima nos fragmentos tumorais e normais.

Os resultados obtidos na presente pesquisa nos levam a concluir que havendo uma relação entre a BzAO e a angiogênese, eventualmente no futuro possam ser desenvolvidas substâncias antiangiogênicas que atuem inibindo esta enzima e por conseguinte também o crescimento tumoral e metastático. Além disso, que talvez possa ser possível utilizar a dosagem da BzAO como um possível marcador tumoral. Enfim, são necessários ainda mais estudos para resultados mais conclusivos. 


\section{Conclusão}

A atividade enzimática registrada nos fragmentos tumorais foi mais elevada em comparação com a dos fragmentos normais, e com significância estatística $(\mathrm{p}<0,05)$. Analisando-se outras possíveis diferenças das dosagens de BzAO quanto ao local de acometimento do tumor, o resultado anatomopatológico, a classificação TNM, número de linfonodos acometidos e a invasão vascular e perineural não foram encontradas diferenças significativas entre os doentes da presente casuística.

\section{Referências}

1. Bergeret $B$, Blaschko H, Hawes R. Occurrence of na amine oxidase in horse serum. Nature 1957; 180: 1127-8.

2. Blaschko $\mathrm{H}$. The amine oxidases of mammalian blood plasma. Adv Comp Physiol Biochem 1962; 1: 67-116.

3. McEwen Jr. CM, Cohen JD. An amino oxidase in normal human serum. J Lab Clin Med 1963; 62:766-76.

4. McEwen Jr. CM. Human plasma amoni oxidase: I. Purification and identification. J Biol Chem 1965; 240: 2003-10.

5. McEwen Jr., CM. Human plasma monoamine oxidase: II. Kinectic studies. J Biol Chem 1965; 240: 2011-8.

6. Tabor CW, Tabor H, Rosenthal SM. Purification of amine oxidase from beef plasma. J Biol Chem 1954; 208 : 645-61.
7. Lewinsohn R. Benzylamine oxidase: an anzyme in search of a function [Tese - Doutorado]. Universidade de Londres; 1980.

8. Lewinsohn R, Araújo M. Benzilamino-oxidase (BzAO) em tecidos e soros humanos : um marcador de câncer? Anais do XXII Congresso Brasileiro de Cirurgia, Recife; 1997.

9. Ministério da Saúde. Instituto Nacional do Câncer. Coordenação de Programas de Contrôle de Câncer. "O Problema do Câncer no Brasil". Rio de Janeiro: Editora Ministério da Saúde; 1997.

10. Lewinsohn R. Human serum amino oxidase. Enzyme activity in severily burnt patients and in patients with cancer. Clin Chim Acta 1977; 81:247-56.

11. Lancet editorial) Benzylamine oxidase. 1978; I:483.

12. Lewinsohn R, Böhm K-H, Glover V, Sandler M. A benzylamine oxidase distinct from monoamine oxidase B-widespread distribution in man and rat. Biochem Pharmacol 1978; 27 : 1857-63.

13. Ryder TA, MacKenzie ML, Pryse-Davies J, Glover V, Lewinsohn R, Sandler M. A coupled peroxidatic oxidation technic for the histochemical localization of monoamine oxidase A and B and benzylamine oxidase. Histochemestry 1979;6: 93-100

14. Lewinsohn R. Amine oxidase in human blood vessels and nonvascular smooth muscle. J Pharm Pharmacol 1981;33: 569-75.

15. Folkman J, Browder T, Palmblad J. Angiogenesis research: guidelines for translation to clinical application. Tromb Haemost 2001;86(1):23-33.

Andreollo NA, Baldini Neto L, Toledo JP, Araújo MR, Lopes LR, Lewinsohn R. The benzylamine oxidase in patients with advanced gastric adenocarcinoma. Acta Cir Bras [serial online] 2003 MarApr;18(2). Available from URL: http://www.scielo.br/acb.

ABSTRACT - Purpose: To evaluate the benzylamine oxidase (BzAO), a tissue enzyme located in the middle tunica of the blood vessels specifically in the smooth muscle, in neoplastic and normal fragments removed of surgical specimens resected from patients with advanced gastric adenocarcinoma. Methods: Were included in the study 24 patients (18 males and 6 female, mean age of 55,4 years). Considering the localization of the gastric tumours, 11 were in the antrum, 9 in the body, 2 in the cardia, 1 in the antrum and body and 1 in the fundus. Patients were submitted to total gastrectomy (12 cases) and to subtotal gastrectomy (12 patients) with D2 lymphadenectomy. The findings of $\mathrm{BzAO}$ were correlated with age, sex, localization, hystopatological type and the surgery performed. Results: The enzymatic activity in normal tissues varied from $22,9 \mathrm{mM}$ to 111 $\mathrm{mM}$ (média de 57,1), however, in neoplastic tissues the activity were higher and varied from 35,5 $\mathrm{mM}$ to $148 \mathrm{mM}$ (média de 70,7). Statistical analysis using the $\mathrm{t}$ student test showed significant differences (standard deviation $=2.373$ and $p=0.0263, p<0.05$ ). Conclusion: The enzymatic activity were significant in the gastric tumours fragments, suggesting that there are a correlation between the $\mathrm{BzAO}$ and the angiogenesis, and therefore the possibility of utilization the antiangiogenic therapies to cause the inhibition of the tumor growth and metastases formation.

KEY WORDS - Benzylamine oxidase. Stomach. Gastric adenocarcinoma. Angiogenesis.

Correspondência:

Nelson Adami Andreollo

R. Francisco Humberto Zuppi, 1234

13083-350 Campinas - SP

Tels.: (19)2389-2151 / 9795-4163

nandreollo@hotmail.com
Conflito de interesse: nenhum Fonte de financiamento: CNPq e FAPESP
Data do recebimento: $20 / 10 / 2002$

Data da revisão: 04/11/2002

Data da aprovação: 15/12/2002 